\title{
Pervaporation of Toluene-n-Heptane Mixtures with Hybrid PVC Membranes Containing Inorganic Particles
}

\author{
Leila Aouinti $^{1}$ and Denis Roizard ${ }^{2}$ \\ 1. Université des Sciences et de la Technologie Mohamed Boudiaf (USTO-MB), Faculté de Chimie, BP. 1505 Bir El Djir, Oran \\ 31000, Algeria \\ 2. Laboratory of Reactions and Process Engineering, Université de Lorraine, UMR CNRS 7274, 1 rue Grandville, Nancy 54000, \\ France
}

\begin{abstract}
The design and preparation of hybrid mixed matrix membranes based on PVC (polyvinylchloride) were studied for the separation of toluene- $n$-heptane mixtures by pervaporation. PVC was chosen as the starting organic matrix because it is an inexpensive polymer, possessing a very high selectivity for aromatics. This property is due to the polar macromolecular structure that can induce a specific transfer of aromatic species compared with aliphatic species. To improve the performance of the PVC glassy structure, the incorporation of several inorganic micro- and nanoparticles in the polymer matrix was performed to prepare mixed matrix membranes. The results reported were obtained using several types of clay, i.e., Maghnite, Wyoming, Kaolin and Nanocor, with the goal of improving membrane permeability due to the hybrid network. Our results show that the transport properties of the modified PVC network can be drastically modified by the type and amount of particles used.
\end{abstract}

Key words: Mixed matrix membranes, aromatic permselectivity, pervaporation.

\section{Introduction}

The separation of organic-organic liquid mixtures using membranes has been extensively investigated over several decades due to its great importance in the chemical industry. Alcohol-ether, aromatic-alkane and alkane-alkene mixtures are among the most studied of these organic-organic liquid mixtures. The latter mixture is the most difficult to separate using a membrane process, but promising results have already been obtained for the two former mixtures [1].

Separation of the aromatic-aliphatic fractions of industrial cuts, such as ethane-ethylene or benzene-cyclohexane, is an important goal in the petrochemical industry. Unfortunately, because the physical properties of the saturated and unsaturated compounds are similar, the conventional industrially used separation methods, i.e., adsorption, distillation,

Corresponding author: Denis Roizard, Ph.D., senior researcher at CNRS, research fields: membrane design, separations of gas and liquid, membrane processes. and liquid-liquid extraction, are not very efficient and can even be energy demanding because of the formation of azeotropes or the lack of significant volatility differences of the close boiling components $[2,3]$. In this context, the development of new separation methods to circumvent this problem is of significant interest, and the use of membrane technologies is foreseen as a promising method to solve this challenge in the field of gas and liquid separations [4-6]. Particularly, for C6-C7 liquid cuts used in gasoline manufacturing, the percentage of aromatics must be controlled and limited to conform to the regulations. Several studies have shown the possibility of using pervaporation to remove the aromatic components, i.e., the minor component, from their alkane mixtures [7, 8]. However, there are still no commercially available pervaporation membranes.

In this study, PVC (polyvinylchloride), a low-cost polymer, was used as a highly selective hosting matrix, and the improvement of its pervaporation properties 
was achieved by incorporating inorganic fillers into the organic network that are also selective for aromatics. PVC is a glassy polymer $\left(\mathrm{Tg}=82{ }^{\circ} \mathrm{C}\right)$ with low transport properties for hydrocarbons. PVC was primarily chosen because of its medium polarity, as shown by a solubility parameter $\left(\delta_{\mathrm{PVC}}\right)$ of $19.2 \mathrm{MPa}^{1 / 2}$; hence, it is close to the solubility parameters of aromatics (e.g., $\delta_{\text {Benzene }}=18.8 \mathrm{MPa}^{1 / 2}$ and $\delta_{\text {Toluene }}=$ 18.2 $\mathrm{MPa}^{1 / 2}$ ) and significantly higher than the solubility parameters of aliphatic compounds, e.g., $\delta_{\text {hexane }}=14.9 \mathrm{MPa}^{1 / 2}$ and $\delta_{\text {heptane }}=15.1 \mathrm{MPa}^{1 / 2}[9]$. These values indicate that PVC must have high affinities for aromatic structures and relatively low affinities for nonpolar aliphatic structures $[10,11]$.

A literature review shows that few papers have focused on $\mathrm{PVC} / \mathrm{clay}$ systems to evaluate the pervaporation (PV) properties of PVC-based mixed matrix materials, whereas many other polymer/clay membranes have already been studied.

For example, polyamide/clay membranes were studied for the PV of aqueous ethanol mixtures. The organo-clay was prepared by an ion-exchange reaction between the montmorillonite silicate layers and SDS (sodium dodecyl sulfate) as the intercalating agent. The permeation rate was found to decrease, and the separation factor was found to increase upon the insertion of $2 \mathrm{wt} . \%$ SDS-nanoclay in the membranes [12].

Poly(vinyl alcohol)-based mixed matrix membranes loaded with 5 and $10 \mathrm{wt} . \%$ of sodium montmorillonite (NaMMT) were used to dehydrate the aqueous mixtures of isopropanol and 1,4-dioxane. The water selectivity was also found to increase from 1116 to 2241 for PVA/NaMMT composite membranes, whereas the corresponding flux values $(=0.07 \mathrm{~kg}$ $\mathrm{h}^{-1} \mathrm{~m}^{-2}$ ) were lower than the reference value [13].

Kuila et al. [14] prepared a blended membrane containing $25 \%$ SA (sodium alginate) and $75 \%$ sodium CMC (carboxy methyl cellulose), which showed optimum flux and benzene selectivity for 19.6 wt.\% benzene in cyclohexane. The blends containing
CMC above 75 wt.\% were not stable during the pervaporation experiment. This blended membrane was then filled with a $2 \%, 4 \%, 6 \%$ and $8 \%$ organophilic bentonite filler to obtain four filled membranes.

The filled membrane with an 8 wt. $\%$ of organophilic bentonite filler showed a lower flux value $\left(35.6 \mathrm{~kg} \cdot \mu \mathrm{m} \cdot \mathrm{m}^{-2} \cdot \mathrm{h}^{-1}\right)$ than the unfilled membrane $\left(77 \mathrm{~kg} \cdot \mu \mathrm{m} \cdot \mathrm{m}^{-2} \cdot \mathrm{h}^{-1}\right.$ ), but the separation factor for benzene was significantly higher $(\alpha=212)$ than the unfilled membrane ( $\alpha=88.7)$.

Mixed matrix PVC membranes with Maghnite- $\mathrm{H}$ clay as the filler were previously studied by the authors [15]. It was shown that these membranes were also water selective for azeotropic ethanol-water mixtures. Under ambient conditions, a separation factor $\left(\alpha \mathrm{H}_{2} \mathrm{O}\right)$ of 25 and a flux of $11.9 \mathrm{~g} \mathrm{~m}^{-2} \mathrm{~h}^{-1}$ were obtained for $7 \%$ Magh-H content in which in the absence of Magh- $\mathrm{H}$, the corresponding values were 5.8 and $2.3 \mathrm{~g} \mathrm{~m}^{-2} \mathrm{~h}^{-1}$.

Organically modified clay particles prepared by treating with para-toluene sulfonic acid (p-TSA) were incorporated into the sodium alginate $(\mathrm{NaAlg})$ matrix to obtain composite membranes that were tested for PV dehydration of isopropanol (IPA) — water mixtures [16]. The performance of the modified clay-loaded NaAlg composite membrane was compared with that of a pristine clay-loaded NaAlg composite membrane for IPA dehydration.

The 10 wt.\% modified clay-loaded NaAlg membranes showed the highest selectivity of 5.781 with a permeance of $3.423 \mathrm{GPU}$ for $10 \mathrm{wt} . \%$ water containing an isopropanol feed mixture at $30{ }^{\circ} \mathrm{C}$, showing a $140 \%$ higher selectivity compared with the pristine clay-loaded NaAlg composite membrane.

Novel polymer-inorganic hybrid membranes were prepared by incorporating potassium montmorillonite ( $\mathrm{K}^{+} \mathrm{MMT}$ ) into a chitosan (CS) matrix for the dehydration of a water-acetone mixture [17]. The $\mathrm{K}^{+}$ ions in the MMT intergallery could form a hydrated layer with water, which was beneficial for enhancing 
the membrane's selectivity towards water. The membrane doped with $10 \mathrm{wt} . \%$ of $\mathrm{K}^{+}$MMT exhibited the highest performance, with a separation factor of 2.200 , which was nearly 8 times higher than the value of 249 for the pristine $\mathrm{CS}$ membrane at $50{ }^{\circ} \mathrm{C}$ with 5 wt. $\%$ of water in the feed.

Garg et al. [18] prepared poly (dimethyl siloxane) (PDMS)/clay nanocomposite membranes by the in situ cross linking of vinyl terminated PDMS (V-PDMS) resin in the presence of a clay content varying from $1 \% \mathrm{w} / \mathrm{w}$ to $10 \% \mathrm{w} / \mathrm{w}$ to evaluate the influence of layered silicate on the pervaporation characteristics of PDMS. The composite membranes showed higher selectivity for toluene in the separation of toluene/methanol compared with neat PDMS. Meanwhile, for these membranes, the selectivity decreased as the toluene component increased in the feed, but the permeation flux increased.

In the present study, a new set of PVC hybrid membranes containing Maghnite- $\mathrm{H}$ and inorganic nano-clays (Nanocor I30) was studied and characterized for the PV separation of toluene-heptane mixtures. This study compares the obtained results with those from the PVC membrane.

\section{Experimental}

\subsection{Reagents}

PVC, which was kindly provided by ENIP of Skikda (ALGERIA), was used with Maghnite-H or Maghnite- $\mathrm{H}+($ Algerian clays, diameter $\approx 8 \mu \mathrm{m})$ to prepare mixed matrix membranes. Kaolin has an average diameter of approximately $1 \mu \mathrm{m}$. Wyoming montmorillonite (SWY2, diameter $\approx 2.5 \mu \mathrm{m}$ ) was purchased from Clay Minerals Repository (University of Missouri, Columbia). Prior to use, the clay was purified by sedimentation to remove coarse impurities (mainly quartz). Nanocor I30, a nanometric organo-clay, was prepared by the ion exchange of NaMMT with octadecylamine. The average diameters were obtained from laser diffusion measurements (Malvern Mastersizer).

\subsection{Membrane Preparation}

The preparation of pure and composite films (thickness of 60-100 $\mu \mathrm{m}$ ) was performed starting from diluted THF polymer solutions evaporated in molds (diameter $\approx 6 \mathrm{~cm}$ ). For composite films, particular attention was focused on dispersing the inorganic particles in the polymer and promoting a good contact with the polymer phase. Hence, a suspension of clays in THF was slowly added to the polymer solution and was stirred for $24 \mathrm{~h}$ before casting onto Teflon molds. The membranes were allowed to dry at room temperature, and composite films up to $30 \mathrm{wt} . \%$ of clays were prepared. Pure PVC films were colorless, whereas the composite films were brown and were apparently homogeneous with good mechanical properties for a clay content lower than $50 \mathrm{wt} . \%$.

\subsection{Sorption Measurements}

The sorption of the PVC films was performed by immersion in pure liquids at room temperature $(20 \pm$ $1^{\circ} \mathrm{C}$ ) for toluene and $\mathrm{n}$-heptane. The samples, weighing at least $5 \times 10^{-4} \mathrm{~kg}$ each, were maintained in the liquids until the sorption equilibrium was reached, i.e., approximately $24 \mathrm{~h}$. Before each measurement, the samples were rapidly blotted, and the weight increase was recorded using a hermetically closed flask. The measurements were repeated several times to improve the accuracy (relative error: $\pm 3 \%$ ).

The degrees of swelling $(S w)$ were calculated using the following equation:

$$
S w(\%)=100 \times(W \mathrm{~W}-W \mathrm{~d}) / W \mathrm{~d}
$$

where $W_{\mathrm{w}}$ and $W_{\mathrm{d}}$ are the weights of the membrane in the wet and dry states, respectively.

In the case of the clay particles, direct immersion in the liquid was not possible; therefore, the weight increases were measured after the exposure of the particles (approximately $1 \times 10^{-3} \mathrm{~kg}$ ) to the organic vapor in a closed flask. For a given species, the corresponding activity can be evaluated from the partial pressure of the vapor and the saturated partial pressure at the same temperature. Note that in this 
case, the weight increase corresponds to an adsorption phenomena; however, in this study the word "swelling" is used to consider both the absorption and adsorption phenomena occurring with the composite membrane.

\subsection{SEM (scanning electron microscopy)}

The membrane cross-section views were recorded with an SEM using a high-resolution apparatus (Jeol JMS T 330 A).

\subsection{Pervaporation Measurements}

The separation of toluene-heptane mixtures was studied with the PVC composite membranes. A stainless-steel cell was used, and the membrane was placed on a porous support and sealed; the effective membrane diameter in contact with the liquid was $5 \times$ $10^{-2} \mathrm{~m}$. The pressure on the permeate side was maintained below $10^{-3}$ bar [19]. The permeate was collected continuously in glass traps, which were immersed in liquid nitrogen. For a given composite membrane, the PV experiments lasted several days to register the effect of feed composition and of feed temperature; the data were validated when the mean deviation between successive traps was below $\pm 5 \%$ for fluxes and $\pm 2 \%$ for selectivity.

The value of the pervaporation flux is calculated according to the following equation:

$$
\mathrm{J}=\mathrm{M} \text { solvent }(\mathrm{kg}) \cdot\left(1 / \text { Area }\left(\mathrm{m}^{2}\right) .1 / \text { Time }(\mathrm{h})\right)
$$

The flux data are given as flux values normalized to a 1-micron thickness to allow a simple comparison between membranes of different thicknesses. The $C_{\mathrm{p}}$ and $C_{\mathrm{f}}$ values are the weight fractions of either toluene or heptane in the permeate and feed, respectively.

The selectivity parameters used to evaluate the membrane separation are the selectivity factors $\alpha$ and the permeate enrichment $\beta$, which are calculated as follows:

$$
\begin{gathered}
\alpha=\left(C_{\mathrm{pTol}} \mathrm{X} . . C_{\mathrm{fHept}}\right) /\left(C_{\mathrm{fTol}} C_{\mathrm{pHept}}\right) \\
\beta=C_{\mathrm{pTol}} / C_{\mathrm{fTol}}
\end{gathered}
$$

Note that the maximum possible value of $\alpha$ is + infinity, whereas for $\beta$ the maximum is $1 / C_{\mathrm{fTol}}[20] ; \alpha$ and $\beta$ values equal to 1 indicate a transfer without any pervaporation selectivity.

\section{Results}

\subsection{Sorption Properties}

To enhance our understanding of the PV separation mechanism of mixed-matrix membranes, PVC, clays and Nanocor used as fillers, were first subjected to isothermal sorption measurements in each solvent. Table 1 lists the equilibrium sorption capacities recorded at $20{ }^{\circ} \mathrm{C}$. It could be noticed that PVC had a very strong affinity for toluene and that Nanocor was the only filler able to exhibit a clear preferential sorption for toluene (4 times higher than for heptane). For the other fillers, the difference of sorption values between the two solvents was too small to be significant.

These data also revealed strong differences in the sorption capacity, indicating that Maghnite and Nanocor could be better candidates than Kaolin or Wyoming clay to promote PV flux, possibly due to the respective accessible specific surface of the fillers. Therefore, it is fundamental to quantify the sorption extent for each solvent, which translates the amplitude of the interactions between the small molecules and the PV membranes and enables the evaluation of the ideal expected selectivity with a given binary mixture. The difference of the solubility parameters between the polymer and the permeant is often used to qualitatively determine the sorption degree of a given molecule for a polymeric membrane [21]. However, the quantitative evaluation of the sorption degree requires that dedicated experiments are performed.

Table 1 Equilibrium sorption capacity $(\mathrm{g} / \mathrm{g} \%)$ of clays to toluene and heptane at $20{ }^{\circ} \mathrm{C}$.

\begin{tabular}{lllllll}
\hline Clays & PVC & Magh-H (\%) & Magh- $\mathrm{H}^{+}(\%)$ & Kaolin (\%) & Wyoming SWY2 (\%) & Nanocor (\%) \\
\hline n-Heptane vapor & 0.6 & 15.7 & 17.3 & 9.6 & 2.7 & 10 \\
Toluene vapor & 49 & 18.5 & 17.7 & 9.3 & 3.3 & 40 \\
\hline
\end{tabular}


Hence, the sorption properties of the composite PVC - clay membranes were registered with 50-50 wt.\% toluene/n-heptane mixtures in the vapor and liquid phases (Table 2).

The liquid phase sorption values are much larger than are those in the vapor phase for toluene and heptane, and it is noted that the sorption of toluene is always stronger than that of heptane. Given the measurement conditions, the difference in values between the vapor and liquid phases is mainly due to the lower thermodynamic activity of vapor (Table 2).

\subsection{Membrane Morphology}

SEM pictures were obtained to determine whether the effect of the filler at the microscopic level could be seen (Fig. 1). The PVC view can be considered as a reference for a fully dense cross section of the glassy polymer (Fig. 1a); with a magnification of 1500 , the cross section appears neat and homogenous, and only some small defects can be seen.

Conversely, all of the other pictures show heterogeneous surfaces. The hybrid M 30\% Mag-H view exhibits major cracks in the middle and on the right hand side, which corresponds to the bottom side of the membrane (Fig. 1b). It appears that these cracks are due to the agglomeration of fillers, which were the largest used of this series (i.e., the average Maghnite value was $8 \mu \mathrm{m})$. These cracks are not seen in the $\mathrm{M}$ $30 \%$ Kaolin cross-section (Fig. 1c); in this case, the distribution of the fillers appears the same from one side to the other side of the membrane (mean Kaolin value: $1 \mu \mathrm{m}$ ). Fig. $1 \mathrm{~d}$ corresponds to a matrix with 30 wt.\% of Nanocor, which is the smallest filler. It is interesting to note here that the cross section is composed of a multitude of small flakes that seem to be coplanar to the surface. This well-ordered structure must be linked to the platelet morphology of the nanometric organo-clays spread throughout the PVC matrix. Hence, compared with the Kaolin filler, the incorporation of Nanocor fillers in the PVC matrix induces a less dense structure.

\subsection{Pervaporation}

Separation by pervaporation requires the use of dense, non-porous polymer films. It is well recognized that the mas transfer is the result of the solution-diffusion mechanism that combines a thermodynamic step and a kinetic step [22]. Schematically, the performances are initially dependent on the affinities between the permeants and the polymer, which can be easily predicted from the sorption affinities and from the diffusion properties of the small molecules in the polymer matrix. Note that the sorption and diffusion phenomena can either favor or not favor the same molecule. Often, the selectivity registered with a binary mixture is significantly lower than the ideal selectivity that would be predicted from the pervaporation of each pure species; this is due to the coupling phenomenon between the two species, which is in any case, difficult to precisely analyze. Using rubbery polymers, the extent of coupling is typically the highest with organic-organic separations because the extent of polymer swelling can be very high.

\subsection{Effect of the Magh-H Content on Membrane PV Selectivity}

The properties of the composite films were determined with the 50/50 toluene/n-heptane feed

Table 2 The phase sorption equilibrium vapor and liquid at $50 \mathrm{wt.} \%$ toluene-n-heptane mixture.

\begin{tabular}{llll}
\hline Membranes * & PVC & M 50\% Magh H & M 50\% Magh H \\
\hline Heptane, vapor & $1.2 \%$ & $1.4 \%$ & $1.8 \%$ \\
Toluene, vapor & $26.9 \%$ & $12.8 \%$ & $14.9 \%$ \\
Heptane, liquid & $0.6 \%$ & $2.6 \%$ & $3.8 \%$ \\
Toluene, liquid & $48-49 \%$ & $21.5 \%$ & $29.7 \%$ \\
$50 \%$ Toluene- Heptane, liquid & - & $11.8 \%$ & - \\
\hline
\end{tabular}

*Measurement accuracy: $+/-1 \%$ at best. 


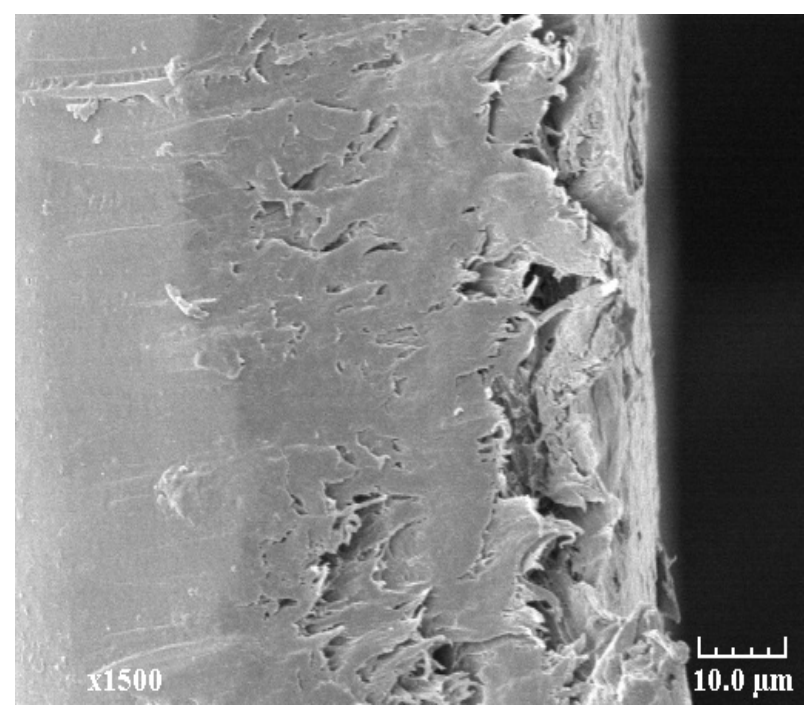

(a)

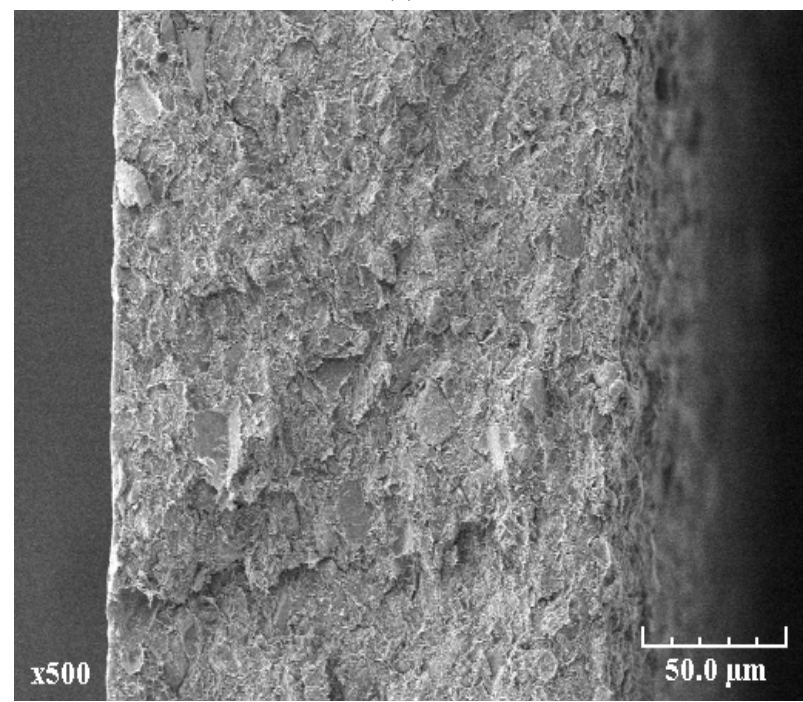

(c)

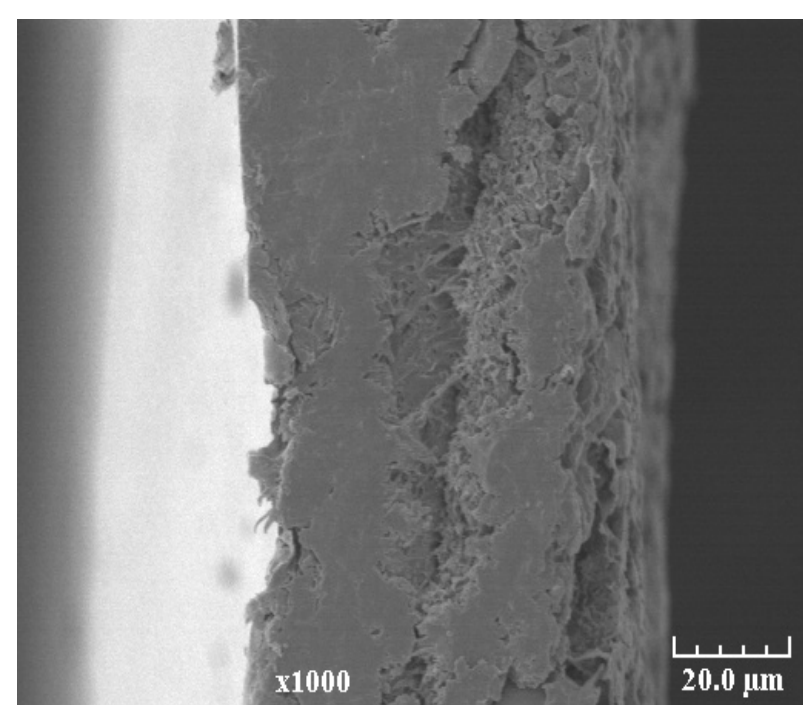

(b)

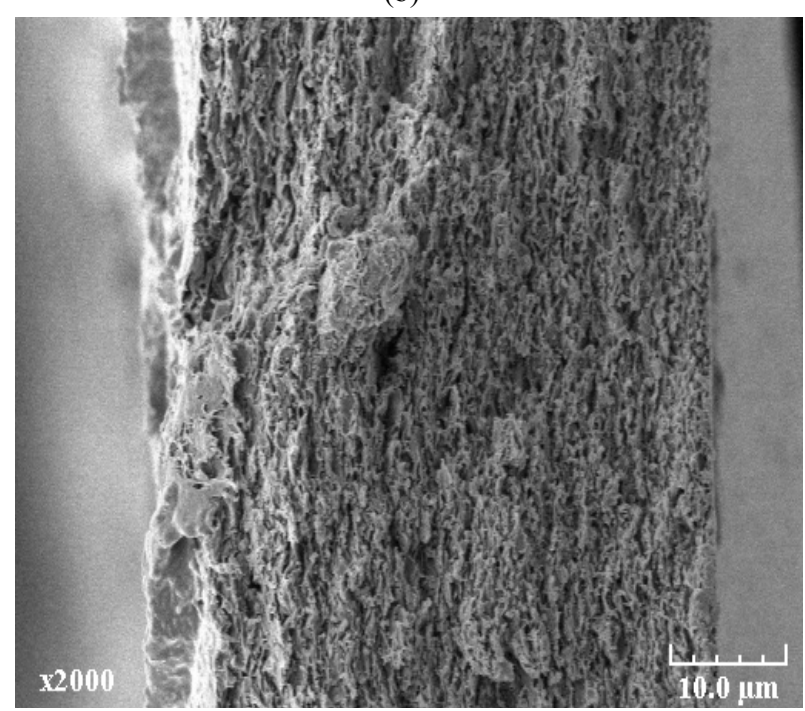

(d)

Fig. 1 Cross-section SEM micrographs: (a) PVC, (b) M30\% Magh-H, (c) M30\% Kaolin, and (d) M30\% Nanocor.

mixture at two temperatures, $54{ }^{\circ} \mathrm{C}$ and $74{ }^{\circ} \mathrm{C}$. The effect of incorporation of the Magh-H on the PV flux and selectivity are presented in Figs. 2 and 3, respectively.

The effect of the membrane composition is more significant on the PV fluxes than on the membrane selectivity. The flux values increased only slightly for 10 wt.\% of Magh-H, whereas for the percentages of 30 and 50 wt.\% of filler, the increase in the flux values was considerable, especially at $74^{\circ} \mathrm{C}$, as shown in Fig. 2.

However, at $74{ }^{\circ} \mathrm{C}$, a sharp increase in flux was observed with the films having the strongest mass contents of Magh-H, i.e., from 20 to $50 \%$; compared with PVC, the flux is approximately 2 times higher (4 kg. $1 \mu \mathrm{m} / \mathrm{h} . \mathrm{m}^{-2}$ ).

For the pure PVC film sand for all of the mixed matrix membranes containing Mag-H, a clear toluene enrichment of the permeate could be obtained, corresponding to a toluene percentage enrichment from $50 \mathrm{wt} . \%$ in the feed to $\approx 80 \mathrm{wt} . \%$ in the permeate for 50 wt.\% Magh-H (Fig. 3).

The pervaporation selectivity appears to be consistent with the results obtained by sorption, 


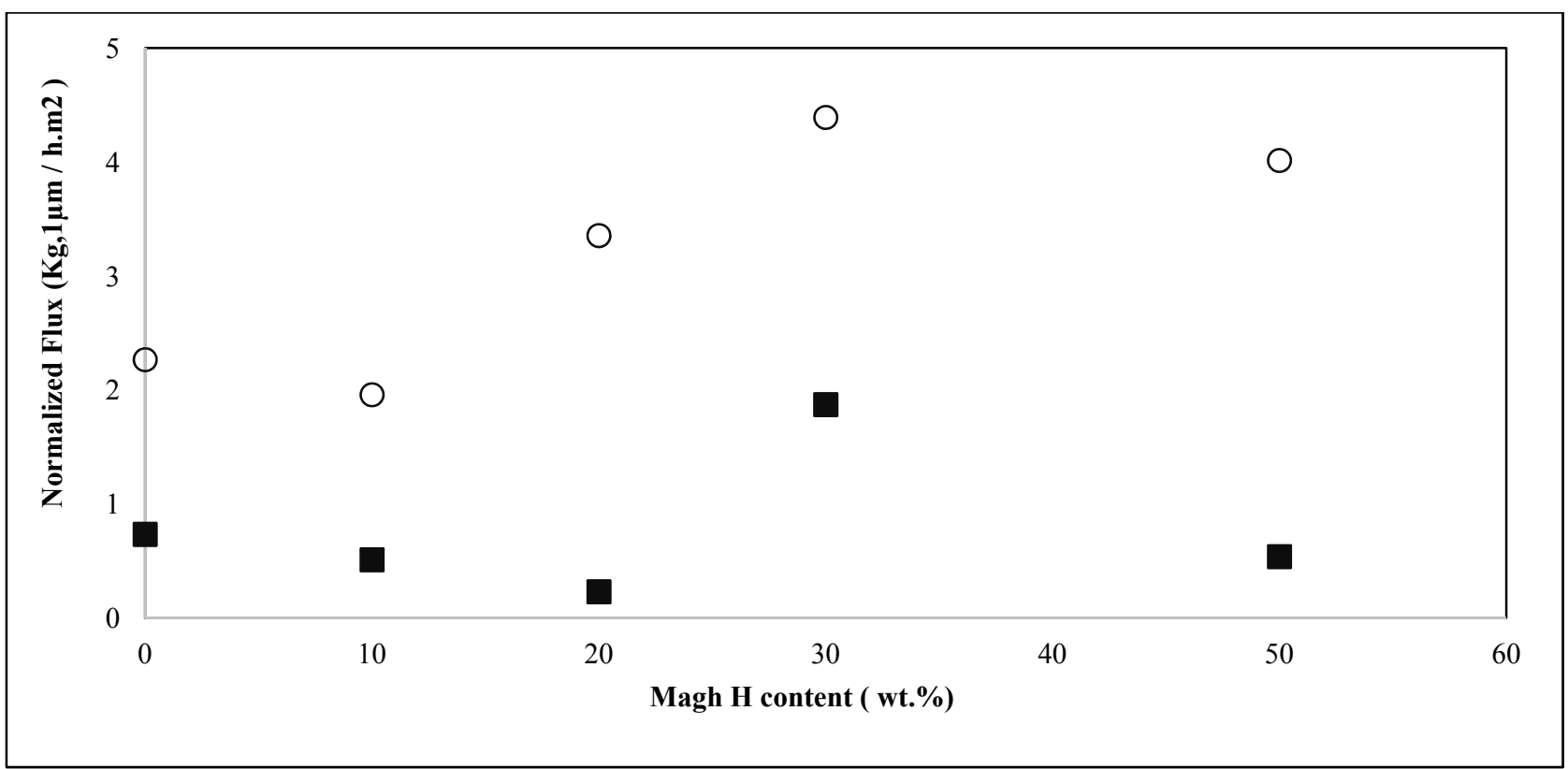

Fig. 2 Effect of the Magh-H content of the composite membranes on the permeate fluxes. Feed concentration: 50 toluene wt.\%, ○: Flux $74{ }^{\circ} \mathrm{C}$, a: Flux $54^{\circ} \mathrm{C}$.

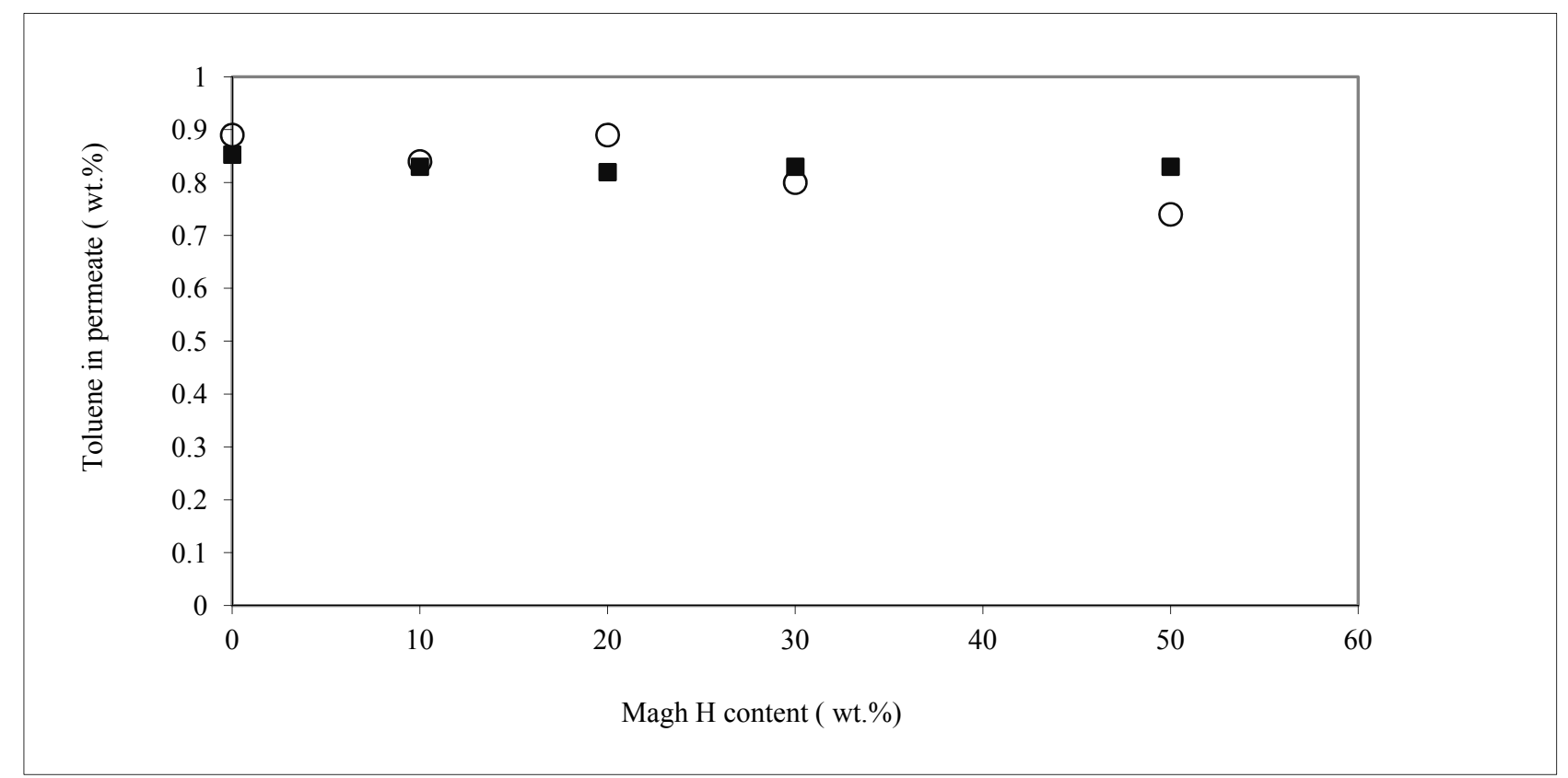

Fig. 3 Effect of the Magh-H content of the composite membranes on the permeate fluxes. Feed concentration: 50 toluene wt.\%, ०: Flux $74^{\circ} \mathrm{C}$, a: Flux $54^{\circ} \mathrm{C}$.

showing a higher affinity for toluene. Magh-H does not have more affinity for toluene than PVC itself; hence, both the pristine and composite membranes lead to a similar selectivity. On the other hand, the increase of flux can be linked to the heterogeneous structures of the films characterized by SEM. The Magh-H particles have an average size of $19 \mu \mathrm{m}$, which is relatively high; this parameter avoids the formation of films with a homogeneous structure, as shown in the SEM views.

\subsection{Membrane Performance}

The results listed in Table 3 exhibit two strikingly different effects induced by the fillers (30 wt.\%) on 
Table 3 Comparative PV results obtained for pure $\mathrm{PVC}$ and loaded films with $30 \mathrm{wt} . \%$ clays $\left(\mathrm{t}=74^{\circ} \mathrm{C}\right)$.

\begin{tabular}{|c|c|c|c|c|c|c|c|}
\hline Performance & PVC & Films +30 wt. $\%$ : & Magh- $\mathrm{H}^{+}$ & Magh-H & SWY & Kaolin & Nanocor \\
\hline $\begin{array}{l}\text { Flux J1 } \mu \mathrm{m} \\
\left(\text { kg.1 } 1 \mu \mathrm{m} \mathrm{h}^{-1} \mathrm{~m}^{-2}\right)^{\mathrm{a}}\end{array}$ & 2.2 & & 4 & 4.4 & 1.4 & 1.9 & 14 \\
\hline $\begin{array}{l}\text { Permeate Toluene } \\
(\mathrm{Cp}, \text { wt. } \%)\end{array}$ & 89 & & 81 & 81 & 85 & 83 & 67 \\
\hline
\end{tabular}

${ }^{\mathrm{a}}$ Flux values normalized to $1-\mu \mathrm{m}$ thickness.

the PV properties of the composite films. On the one hand, considering the lower flux obtained with the Wyoming and Kaolin fillers with respect to the flux of the pure PVC film, one can deduce that these two fillers clearly act as impermeable particles, increasing the tortuosity relative to their smaller average diameters, thus limiting the mass transfer of permeants [23].

Thus, the phenomenon is explained by the barrier effect of the Kaolin and Wyoming particles in which the high shape factor of montmorillonite clay can lead to a large decrease in polymer permeability [24]. The lower permeate enrichment simultaneously registered (Cp: $84 \%$ at $50{ }^{\circ} \mathrm{C}$ ) is less logically explained; it must be the result of very tiny defects induced by the fillers in the composite films. On the other hand, Maghnite fillers and, particularly, Nanocor, led to dramatic flux increases of 200 and $700 \%$, respectively, which could not be attributed to film defects because the corresponding toluene permeate enrichments were still high. Thus, clearly in these cases, the fillers strongly enhanced the permeant mass transfer.

\section{Conclusions}

In this study, several composite membranes were produced using PVC and four different clays. It was shown that the permeation properties of PVC can be strongly modified by the incorporation of fillers, leading either to the reinforcement of its barrier properties (i.e., with Wyoming or Kaolin) or to much higher mass transfer properties (i.e., with Maghnite or Nanocor).

Improved hybrid membrane performances were obtained with Maghnite-H and Nanocor fillers, each of them having a higher affinity for toluene than for heptane. In contrast to separation by distillation, this type of membrane favors the preferential removal of toluene from the liquid feed mixture.

Hence, these results show that a simple and economical polymer, such as PVC, can be used with an appropriate filler to obtain high separation properties for aromatic-alkane mixtures by pervaporation due to the intrinsic PVC affinity for aromatics induced by the polar chlorine atoms of the polymer backbone. To progress towards the potential applications of PVC membranes, thin, supported, dense selective layers should be prepared to drastically increase the permeance while maintaining constant the high selectivity due to the PVC matrix. To achieve the successful preparation of these composite membranes, a key parameter would be to use nanoparticles with improved compatibility with the PVC chains.

\section{References}

[1] Smitha, B., Suhanya, D., Sridhar, S., and Ramakrishna, M. 2004. "Separation of Organic-Organic Mixtures by Pervaporation, a Review." Journal of Membrane Science 241: 1-21.

[2] Aouinti, L., Roizard, D., and Belbachir, M. 2015. "PVC_Activated Carbon Based Matrices: A Promising Combination for Pervaporation Membranes Useful for Aromatic-Alkane Separations." Separation and Purification Technology 147: 51-61.

[3] Keller, G. E., Marcinkowsky, A. E., Verma, S. K., and Williamson, K. D. 1992. "Olefin Recovery and Purification via Silver Complexation." In Separation and Purification Technology, edited by Li, N. N., and Calo, J. M., New York: Marcel Dekker, 59-83.

[4] Sirkar, K. K. 1995. "Membrane Separation Technologies: Current Development and Future Opportunities." In 
Annual Meeting-Recent and Future Opportunities in Separation Technology Vol I. New York: AICHE, 26.

[5] Hughes, R. D., Mahoney, J. A., and Steigelmann, E. F. 1986. "Olefin Separation by Facilitated Transport Membranes." In Recent Developments in Separation Science 9, edited by Li, N. N., and Calo, J. M. Boca Raton, FL: CRC Press, 173-95.

[6] Burns, R. L., and Koros, W. J. 2003. "Defining the Challenges for $\mathrm{C}_{3} \mathrm{H}_{6} / \mathrm{C}_{3} \mathrm{H}_{8}$ Separation Using Polymeric Membranes." Journal of Membrane Science 211: 299-309.

[7] Roizard, D., Nilly, A., and Lochon, P. 2001. "Preparation and Study of Crosslinked Polyurethane Films to Fractionate Toluenen-n Heptane Mixture by Pervaporation." Separation and Purification Technology 22: 45-52.

[8] Uragami, T., Tsukamoto, K., Inui, K., and Miyata, T. 1998. "Pervaporation Characteristics of a Benzoylchitosan Membrane for Benzene-Cyclohexane Mixtures." Macromolecular Chemistry and Physics 199: 49-54.

[9] Okamoto, K., Wang, H., Fujiwara, I. S., Tanaka, K., and Kita, H. 1999. "Pervaporation of Aromatic/Non-Aromatic Hydrocarbon Mixtures through Crosslinked Membranes of Polyimide with Pendant Phosphonate Ester Groups." Journal of Membrane Science 157: 97-105.

[10] Allan, F., and Barton, M. 1979. "Solubility Parameters." Chemical Reviews 75: 731-53.

[11] Neel, J., Aptel, P., and Clement, R. 1985. "Basic Aspects of Pervaporation." Desalination 53: 297-326.

[12] Wang, Y. C., Fan, S. C., Lee, K. R., Li, C. L., Hang, S. H., and Tsai, H. A. 2004. "Polyamide/SDS-Clay Hybrid Nanocomposite Membrane Application to Water-Ethanol Mixture Pervaporation Separation." Journal of Membrane Science 239: 219-26.

[13] Adoor, S., Saraim, M., Manjeshwar, L. S., Raju, K. V. S. N., and Aminabhavi, T. M. 2006. "Sodium Montmorillonite Clay Loaded Novel Mixed Matrix Membranes of Poly (Vinyl Alcohol) for Pervaporation Dehydratation of Ether Aqueous Mixtures." Journal of Membrane Science 285: 192-5.

[14] Kuila, S. B., and Ray, S. K. 2014. "Separation of Benzene-Cyclohexane by Filled Blend Membranes of
Carboxy Methyl Cellulose and Sodium Alginate." Separation and Purification Technology 123: 45-52.

[15] Aouinti, L., and Belbachir, M. 2008. "A Maghnite-Clay-H/Polymer Membrane for Separation of Ethanol-Water Azeotrope." Journal Applied Clay Science 39 (1-2): 78-85.

[16] Suhas, D. P., Aminabhavi, T. M., and Raghu, A. V. 2014. "Para-Toluene Sulfonic Acid Treated Clay Loaded Sodium Alginate Membranes for Enhanced Pervaporative Dehydration of Isopropanol." Applied Clay Science 101: 419-29.

[17] Gao, C., Zhang, M., Jiang, Z., Liao, J., Xie, X., Huang, T., Zhao, J., Bai, J., and Pan, F. 2015. "Preparation of a Highly Water-Selective Membrane for Dehydration of Acetone by Incorporating Potassium Montmorillonite to Construct Ionized Water Channel." Chemical Engineering. Science, in press. http://dx.doi.org/10.1016/j.ces.2014.12.044i.

[18] Garg, P., Singh, R. P., and Choudhary, V. 2011. "Pervaporation Separation of Organic Azeotrope Using Poly(Dimethyl Siloxane)/Clay Nanocomposite Membranes." Separation and Purification Technology 80: 435-44.

[19] Roizard, D., Clément, R., Kerres, J., and Eigenberger, G. 1996. "Synthesis Characterization and Transport Properties of a New Siloxane-Phosphazene Copolymer." Journal of Membrane Science 113: 151-60.

[20] Néel, J. 1997. Pervaporation, Technique et Document. Paris: Lavoisier.

[21] Shriver, D. F., Atkins, P. W., and Langford, C. H. 1992. Inorganic Chem. Oxford: Oxford University Press, Chapter.13.

[22] Zimmerman, C., Singh, A., and Koros, W. 1997. "Tailoring Mixed Matrix Composite Membranes." Journal of Membrane Science 137 (1-2): 145-54.

[23] Wijmans, J. G., and Baker, R. W. 1995. "The Solution-Diffusion Model: A Review." Journal of Membrane Science 107 (1-2): 1-21.

[24] Chen, G., Yao, G., and Zhao, J. 1999. "Montmorillonite Clay/Poly (Methyl Methacrylate) Hybrid Resin and Its Barrier Property to the Plasticizer within Poly (Vinyl Chloride) Composite." Journal Applied Polymer Science 73: 425-30. 